\title{
Plantar Loading During Cutting While Wearing a Rigid Carbon Fiber Insert
}

\author{
Robin M. Queen, PhD*t; Alicia N. Abbey, BS, ATC*†; Ravi Verma, BS*; Robert \\ J. Butler, DPT, PhD‡; James A. Nunley, MD†
}

*Michael W. Krzyzewski Human Performance Laboratory, Duke University, Durham, NC; †Department of Orthopaedic Surgery and ¥Department of Community and Family Medicine, Duke University Medical Center, Durham, NC

Context: Stress fractures are one of the most common injuries in sports, accounting for approximately $10 \%$ of all overuse injuries. Treatment of fifth metatarsal stress fractures involves both surgical and nonsurgical interventions. Fifth metatarsal stress fractures are difficult to treat because of the risks of delayed union, nonunion, and recurrent injuries. Most of these injuries occur during agility tasks, such as those performed in soccer, basketball, and lacrosse.

Objective: To examine the effect of a rigid carbon graphite footplate on plantar loading during 2 agility tasks.

Design: Crossover study.

Setting: Laboratory.

Patients or Other Participants: A total of 19 recreational male athletes with no history of lower extremity injury in the past 6 months and no previous metatarsal stress fractures were tested.

Main Outcome Measure(s): Seven $45^{\circ}$ side-cut and crossover-cut tasks were completed in a shoe with or without a fulllength rigid carbon plate. Testing order between the shoe conditions and the 2 cutting tasks was randomized. Plantar- loading data were recorded using instrumented insoles. Peak pressure, maximum force, force-time integral, and contact area beneath the total foot, the medial and lateral midfoot, and the medial, middle, and lateral forefoot were analyzed. A series of paired $t$ tests was used to examine differences between the footwear conditions (carbon graphite footplate, shod) for both cutting tasks independently $(\alpha=.05)$.

Results: During the side-cut task, the footplate increased total foot and lateral midfoot peak pressures while decreasing contact area and lateral midfoot force-time integral. During the crossover-cut task, the footplate increased total foot and lateral midfoot peak pressure and lateral forefoot force-time integral while decreasing total and lateral forefoot contact area.

Conclusions: Although a rigid carbon graphite footplate altered some aspects of the plantar- pressure profile during cutting in uninjured participants, it was ineffective in reducing plantar loading beneath the fifth metatarsal.

Key Words: soccer, cross cutting, side cutting, plantar pressure, fifth metatarsal fracture, rigid carbon graphite footplate

Key Points

- Fifth metatarsal stress fractures can be difficult to treat because of the risks of delayed union, nonunion, and recurrent injury.

- In combination with a custom orthotic and foot brace, modifying footwear with the use of a carbon graphic footplate has been proposed to allow athletes to safely return to sport while the stress fracture is healing.

- Plantar loading beneath the fifth metatarsal increased in healthy participants who wore a carbon graphite footplate while performing agility tasks. Plantar loading with and without the footplate should be studied in patients with metatarsal fractures.

$\mathrm{W}$ hile athletes compete in sports, the risk of injury depends upon the sport and position being played. ${ }^{1}$ Age, sex, competition level, bone density, and shoe type are all risk factors for injuries related to the foot and ankle. ${ }^{2-4}$ Stress fractures are one of the most common time-loss bony injuries in sports, accounting for approximately $10 \%$ of all overuse injuries. ${ }^{5}$ Metatarsal stress fractures account for up to $25 \%$ of all stress fractures in the foot. ${ }^{4}$ In addition to the previously mentioned risk factors, other risk factors appear to be associated with fifth metatarsal stress fractures, such as foot morphology, shoe design, and athletic task. ${ }^{4}$ The literature examining foot type as a risk factor for fifth metatarsal stress fractures is inconclusive, with some studies indicating that individuals with a flat foot were at increased risk for fracture ${ }^{6}$ and others indicating that those with a high arch foot were at increased fracture risk. ${ }^{7}$ Treatment of fifth metatarsal stress fractures involves both surgical and nonsurgical interventions. Regardless of treatment, however, fifth metatarsal stress fractures are difficult to treat ${ }^{8-12}$ because delayed union, nonunion, and recurrent injury are frequent complications. ${ }^{9,11,13-15}$

The role of sex in fifth metatarsal stress fractures is not well understood. However, of the 23 fifth metatarsal stress fractures studied by Porter et al, ${ }^{3} 17$ occurred in men. Although differences in the incidence of injury between sexes have limited research support, sex differences in plantarloading magnitude and increased lateral foot loading in men have been reported in multiple studies. ${ }^{16-18}$ In addition, investigators ${ }^{19}$ have shown that fifth metatarsal stress fractures are more common in sports such as soccer, basketball, and lacrosse, which require cutting and other agility tasks. 


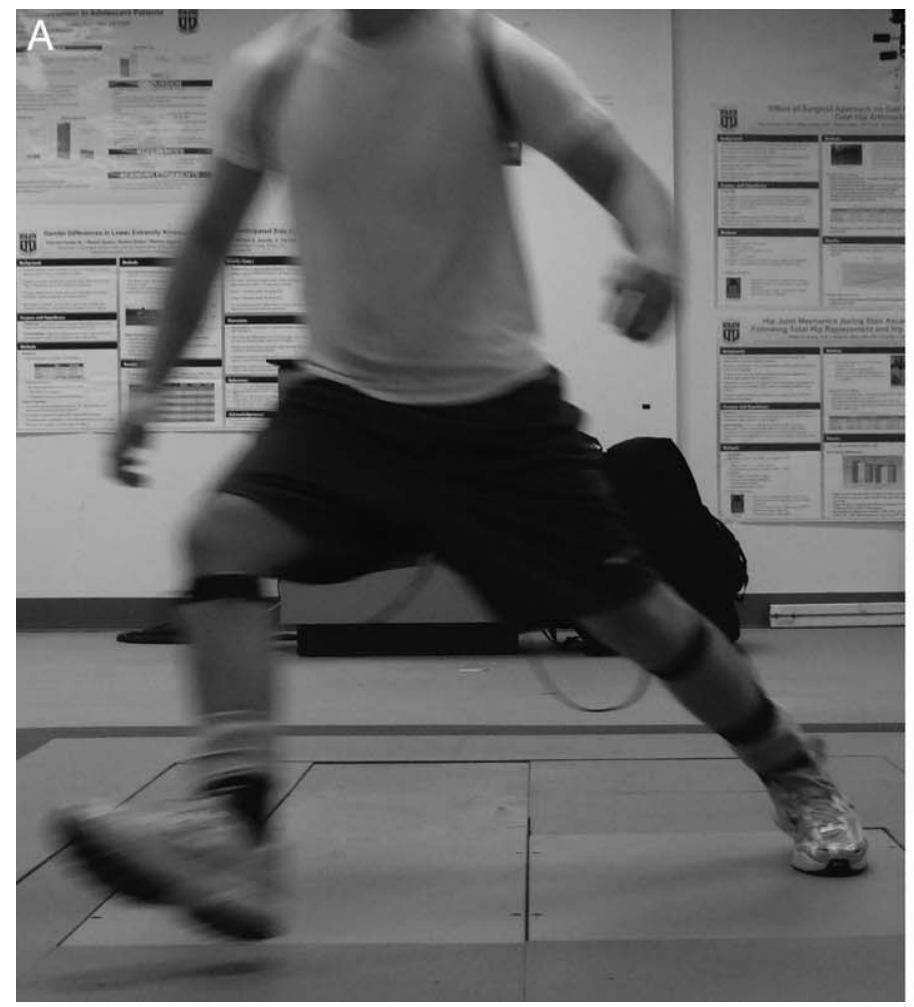

Figure 1. A, The side cut. B, The crossover cut.

The effects of side cuts, crossover cuts, and forward acceleration on plantar loading have been examined. ${ }^{20-22}$ Queen et al, ${ }^{20}$ Eils et al, ${ }^{21}$ and Wong et $\mathrm{al}^{22}$ demonstrated that a $45^{\circ}$ or $180^{\circ}$ side-cutting task (to either side) resulted in increased plantar loading under the medial column of the foot. With the crossover cut, however, the increase in plantar loading shifted to the lateral forefoot. ${ }^{20}$ This increase in plantar loading beneath the lateral column indicates the importance of evaluating crossover cuts when examining potential risk factors for fifth metatarsal stress fractures. The conservative management of fifth metatarsal stress fractures has often resulted in delayed union or nonunion of these fractures, especially in athletes..$^{9,11,13-15}$ A novel technique is showing success in the conservative treatment of these fractures. Combining a custom orthotic and foot brace and modifying footwear through the use of a carbon graphite footplate allowed players to return to sport while the fractures were healing; no delayed unions or nonunions occurred. ${ }^{23}$

Based on this work, the purpose of our study was to quantify the effect of a rigid carbon graphite footplate on plantar loading, as defined by contact area, maximum force, and the localized force-time integral, during side cuts and crossover cuts. We hypothesized that a rigid carbon graphite footplate would decrease plantar loading beneath the lateral aspect of the foot during the cutting tasks and, therefore, be beneficial in the conservative treatment of stress fractures.

\section{METHODS}

A total of 19 college-aged physically active males (age $=$ $21.4 \pm 2.41$ years, height $=1.78 \pm 0.07 \mathrm{~m}$, mass $=75.45$ $\pm 8.69 \mathrm{~kg}$, body mass index $=23.7 \pm 1.7$ ) volunteered

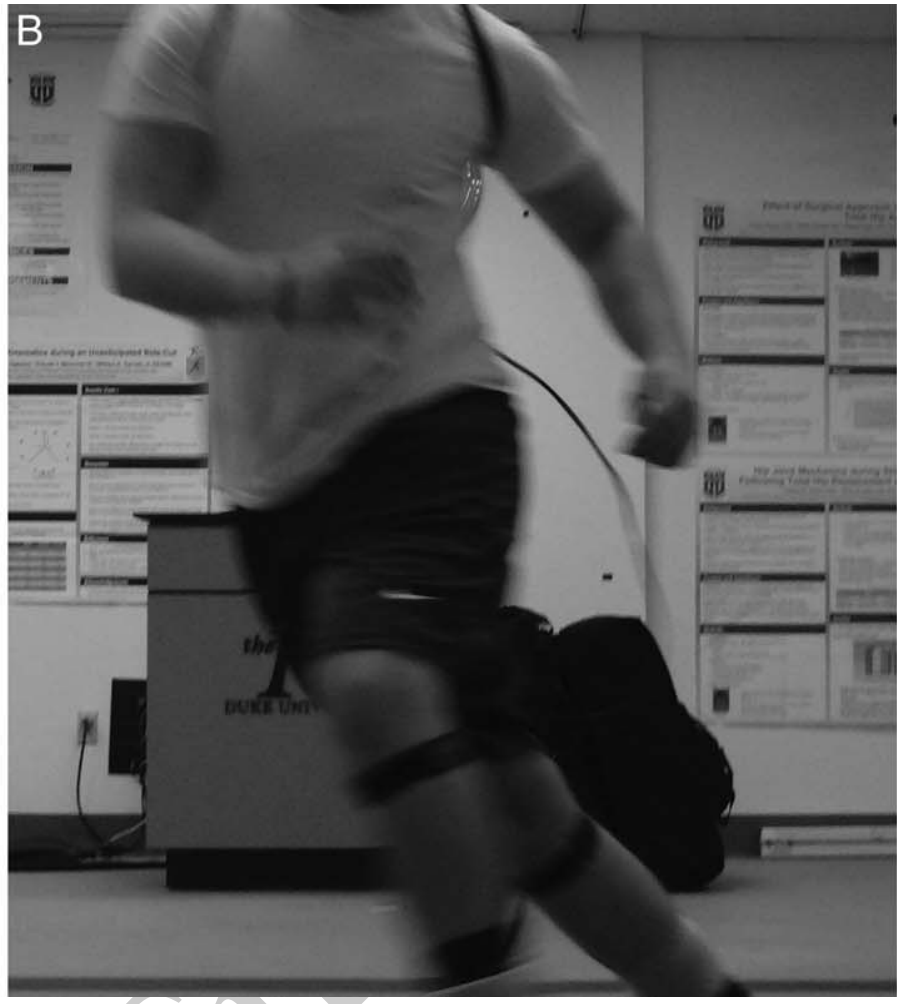

for the study. They were physically active and engaged in sports that require cutting-type maneuvers, such as soccer and basketball, and had no history of lower extremity injury in the past 6 months, foot or ankle surgery in the past 3 years, or previous metatarsal stress fractures. Physically active was operationally defined as participating in physical activity at least 3 times per week for approximately 1 hour each time. Each volunteer read and signed an informed consent that had been approved by the medical center institutional review board, which also approved the study.

A Pedar-X in-shoe pressure measurement system (Novel, St. Paul, MN) was used to collect plantar-pressure data. The insoles were placed bilaterally, and plantar-pressure data were sampled at $100 \mathrm{~Hz}$ via Bluetooth technology. Participants were fitted with appropriate-sized shoes, insoles, and rigid carbon graphite footplates for testing. The rigid carbon graphite footplates were manufactured by Dynaflex and are non-custom, full-length inserts. The Pedar-X insole was placed between the foot and either the carbon insert or the shoe, depending on the testing condition. All testing was completed in the laboratory on standard flooring with participants wearing the Nike Air Pegasus (Nike, Inc, Beaverton, OR), which is a neutral cushioning running shoe. These running shoes were used to standardize footwear equipment among participants and to prevent them from slipping on the laboratory floor during the cutting tasks.

Each participant was asked to run at $75 \%$ of maximum speed and then cut $45^{\circ}$; the direction depended on whether the task was a side cut or crossover cut. We monitored approach speed with a set of photocells to ensure that speed remained within $5 \%$ for all trials at the time of collection for each person in each condition. The side-cut task 


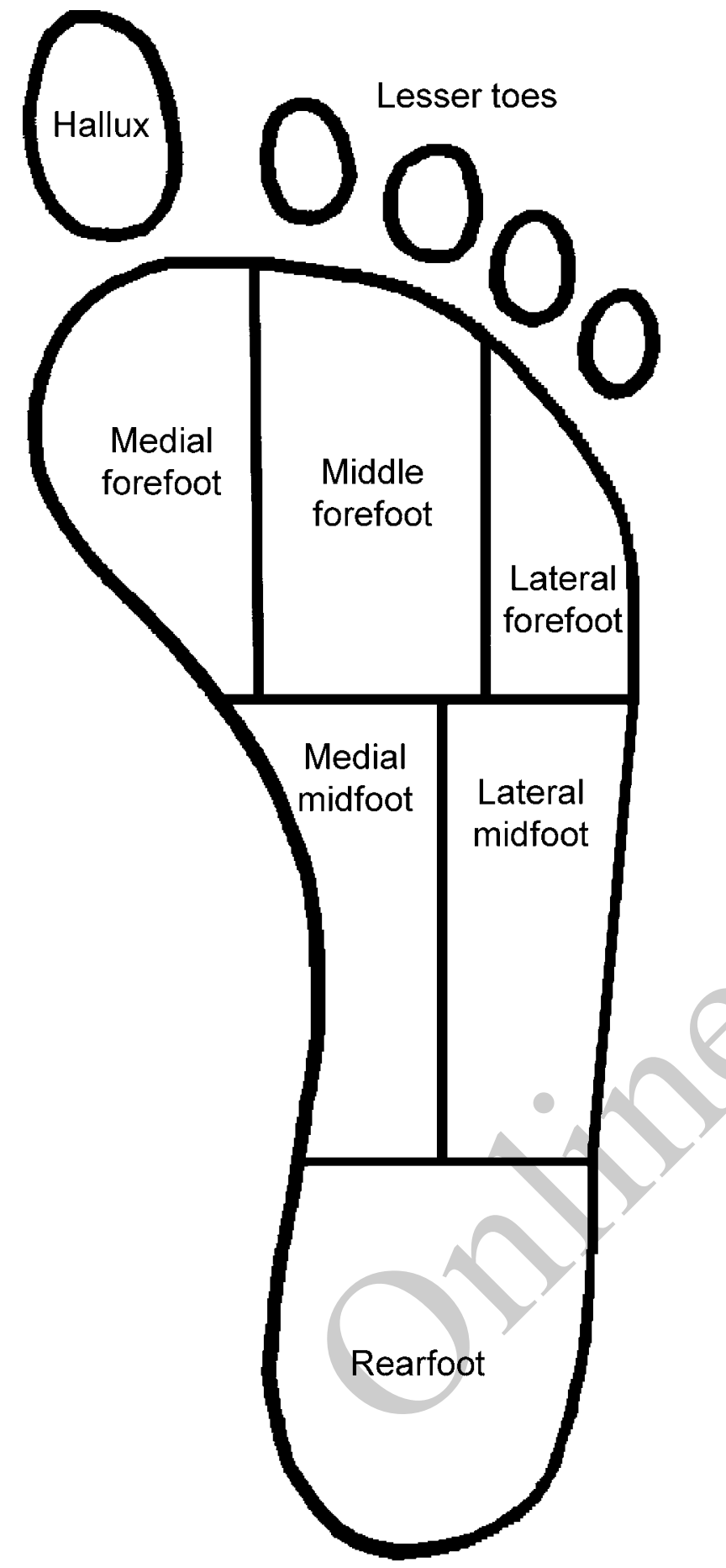

Figure 2. Representation of the masks that were used to divide the foot into 8 anatomical regions in the Novel software (St Paul, MN) during data reduction.

consisted of a left or right foot plant, depending on the dominant leg based on participant comfort, followed by a cut away from the plant leg at $45^{\circ}$ (Figure 1A). The crossover cut was performed by having the participant run forward along a 10-m runway and plant either the right foot or the left foot, depending on plant-foot preference, and then cut across the leg at $45^{\circ}$ (Figure 1B). The participant approached each cut with at least 4 steps before the cut and 3 steps after the cut. Each person was shown how to

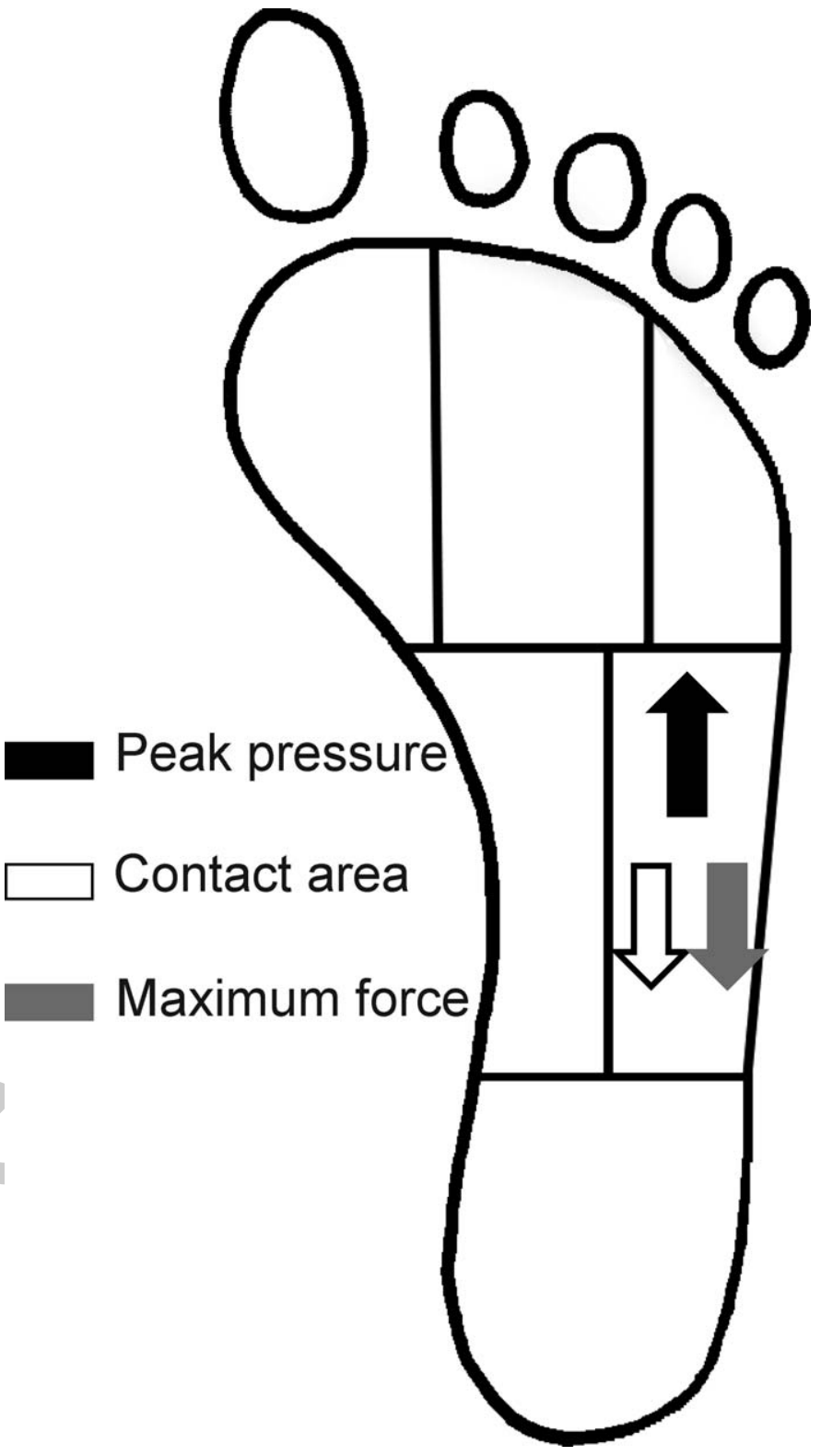

Figure 3. Changes in regional plantar pressure during the sidecutting task. Arrow indicates change in the variable when the carbon fiber footplate was worn in the shoe.

perform the cutting tasks and allowed to choose which foot to use to perform the maneuvers based on comfort. After completing the cutting tasks, the plant leg was isolated from each maneuver for the pressure analysis.

Testing order was randomized for both footwear cutting and condition to avoid fatigue and learning effects. Once the randomization order for footwear condition and task was determined, each participant completed 7 acceptable trials for the given condition before moving on to the next condition. Therefore, if a person was randomized to the carbon graphite footplate and side-cut condition first, he was asked to complete 7 trials in that condition before moving to the other 3 testing conditions. The participant was given a 30 -second rest between trials and a 5-minute rest between testing conditions.

For analysis, the foot was divided into 8 anatomical regions (rearfoot, medial midfoot [MMF], lateral midfoot 
Table 1. Peak Pressure During the Side-Cutting Task, kPA

\begin{tabular}{|c|c|c|c|c|}
\hline \multirow[b]{3}{*}{ Foot Region } & \multicolumn{4}{|c|}{ Shoe Condition } \\
\hline & \multicolumn{2}{|c|}{ No Insert } & \multicolumn{2}{|c|}{ Insert } \\
\hline & Mean $\pm S D$ & $95 \%$ Confidence Interval & Mean $\pm S D$ & $95 \%$ Confidence Interval \\
\hline Total foot ${ }^{\mathrm{a}}$ & $525.48 \pm 129.06$ & $583.52,467.45$ & $811.18 \pm 159.10$ & $882.72,739.64$ \\
\hline Rearfoot & $341.10 \pm 152.11$ & $409.50,272.70$ & $624.51 \pm 276.42$ & $748.80,500.22$ \\
\hline Medial midfoot & $238.39 \pm 93.80$ & $280.56,196.21$ & $249.86 \pm 134.44$ & $310.31,189.41$ \\
\hline Lateral midfoot $^{\mathrm{a}}$ & $204.68 \pm 55.65$ & $229.70,179.66$ & $238.42 \pm 75.44$ & $272.34,204.49$ \\
\hline Mid forefoot & $371.26 \pm 101.99$ & $417.12,325.39$ & $531.29 \pm 200.97$ & $621.66,440.93$ \\
\hline Lateral forefoot & $244.35 \pm 64.33$ & $273.28,215.42$ & $259.23 \pm 121.39$ & $313.81,204.64$ \\
\hline Hallux & $477.67 \pm 140.03$ & $540.64,414.71$ & $692.57 \pm 202.31$ & $783.54,601.60$ \\
\hline Lesser toes & $305.17 \pm 78.71$ & $340.56,269.77$ & $382.15 \pm 156.88$ & $452.69,311.62$ \\
\hline
\end{tabular}

a Difference between shoe conditions.

[LMF], medial forefoot [MFF], middle forefoot [MidFF], lateral forefoot [LFF], hallux, and lesser toes) using a percentage mask in the Novel Multiproject-ip software $^{20,21,24-26}$ (Figure 2). The maximum force, force-time integral, contact time, contact area, and peak pressure were collected for the total foot area and each anatomical region. The results of the 7 trials were averaged. Maximum force is the peak force in the region of interest throughout the entire stance phase. Contact area is the percentage of an area of the insole that was activated during the stance phase relative to the entire contact area of the insole. Force-time integral is the area under the force-time curve and measures both the magnitude of load on an area and the duration of the loading during the stance phase. Maximum force was normalized to each person's body weight, and contact area was normalized to the entire insole contact area. ${ }^{20}$

We used a series of paired $t$ tests $(\alpha<.05)$ to determine if any differences existed between footwear conditions for any study variable independently for the 2 tasks. The choice of paired $t$ tests was based on previous work ${ }^{27}$ indicating differences in loading based on task (side cut versus cross cut) and, therefore, this comparison was not needed in our study. The question of interest was not whether differences existed between the cutting tasks but specifically what the effect of the insert was on plantar loading during these tasks independently. Although the Pedar- X measurement system collects pressure data from all parts of the foot, we analyzed the MMF, LMF, MFF, MidFF, and LFF because our focus was the loads under the lateral column of the foot (LMF and LFF). Focusing on these regions of the foot decreased the need for statistical adjustments due to multiple comparisons.

\section{RESULTS}

\section{Side-Cut Task}

The total foot peak pressure $(P<.001)$ and the LMF peak pressure $(P=.017)$ were increased by $54 \%$ and $17 \%$, respectively, with the rigid carbon graphite footplate (Table $1)$. The force-time integral $(P<.001$; Table 2$)$, total foot contact area $(P=.001)$, and LMF contact area $(P=.007$; Table 3) were decreased by $28 \%, 9 \%$, and $15 \%$, respectively, with the use of the footplate (Figure 3 ). The changes in maximum force in the various foot regions during the side-cut task can be found in Table 4. No differences existed between the footplate conditions for the remaining regions of the foot.

\section{Crossover-Cut Task}

With the rigid carbon footplate, the total foot peak pressure $(P<.001$; Table 5$)$, LMF peak pressure $(P<$ $.001)$, and LFF force-time integral $(P=.016$; Table 6) increased by $60 \%, 37 \%$, and $15 \%$, respectively The total foot contact area $(P<.001)$ and LFF contact area $(P=$ .014 ; Table 7 ) were decreased by $9.7 \%$ and $4.8 \%$, respectively, with the footplate (Figure 4 ). The changes in maximum force in the various foot regions during the

Table 2. Force-Time Integral During the Side-Cutting Task, ns

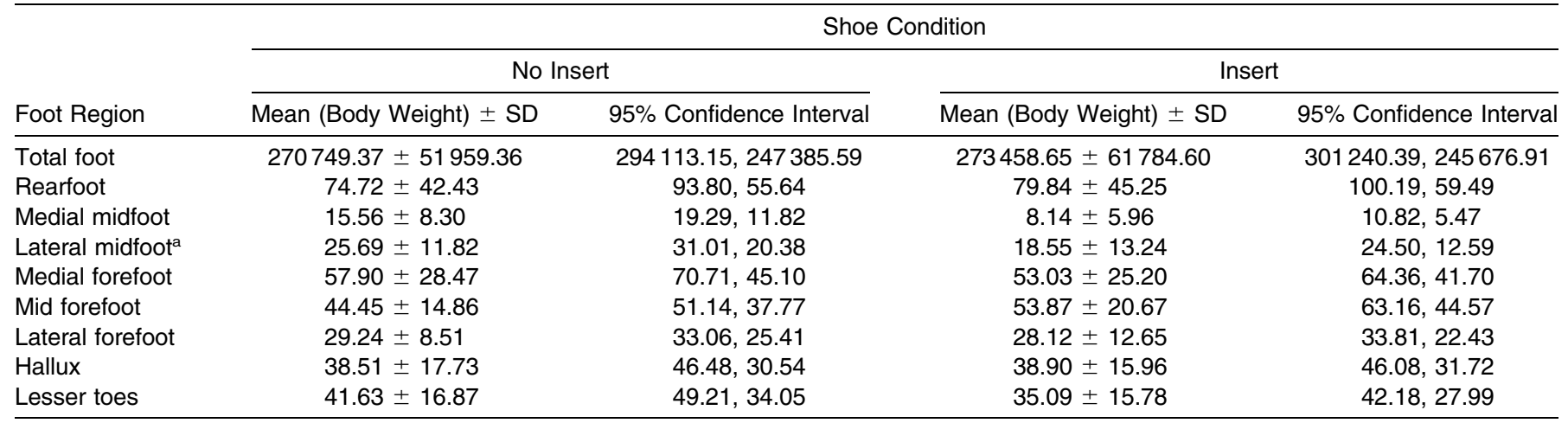

a Difference between shoe conditions. 
Table 3. Contact Area During the Side-Cutting Task, Normalized Insole Contact Area

\begin{tabular}{|c|c|c|c|c|}
\hline \multirow{4}{*}{$\begin{array}{l}\text { Foot } \\
\text { Region }\end{array}$} & \multicolumn{4}{|c|}{ Shoe Condition } \\
\hline & \multicolumn{2}{|c|}{ No Insert } & \multicolumn{2}{|c|}{ Insert } \\
\hline & & $\begin{array}{c}95 \% \\
\text { Confidence }\end{array}$ & & $\begin{array}{c}95 \% \\
\text { Confidence }\end{array}$ \\
\hline & Mean \pm SD & Interval & Mean \pm SD & Interval \\
\hline Total foot ${ }^{a}$ & $0.92 \pm 0.073$ & $0.95,0.88$ & $0.84 \pm 0.09$ & $0.88,0.80$ \\
\hline Rearfoot & $0.24 \pm 0.03$ & $0.25,0.22$ & $0.23 \pm 0.03$ & $0.24,0.22$ \\
\hline Medial midfoot & $0.12 \pm 0.04$ & $0.13,0.10$ & $0.09 \pm 0.04$ & $0.11,0.07$ \\
\hline Lateral midfoot $^{\mathrm{a}}$ & $0.15 \pm 0.01$ & $0.15,0.14$ & $0.13 \pm 0.04$ & $0.11,0.14$ \\
\hline Medial forefoot & $0.07 \pm 0.01$ & $0.08,0$ & $0.07 \pm 0.01$ & $0.07,0.07$ \\
\hline Mid forefoot & $0.09 \pm 0.003$ & $0.09,0.08$ & $0.09 \pm 0.004$ & $0.09,0.08$ \\
\hline Lateral forefoot & $0.08 \pm 0.003$ & $0.08,0.08$ & $0.08 \pm 0.01$ & $0.08,0.08$ \\
\hline Hallux & $0.06 \pm 0.01$ & $0.06,0.06$ & $0.06 \pm 0.01$ & $0.06,0.05$ \\
\hline Lesser toes & $0.11 \pm 0.01$ & $0.11,0.10$ & $0.10 \pm 0.01$ & $0.11,0.09$ \\
\hline
\end{tabular}

a Difference between shoe conditions.

Table 4. Maximum Force During the Side-Cutting Task, Body Weight

\begin{tabular}{|c|c|c|c|c|}
\hline \multirow[b]{3}{*}{ Foot Region } & \multicolumn{4}{|c|}{ Shoe Condition } \\
\hline & \multicolumn{2}{|c|}{ No Insert } & \multicolumn{2}{|c|}{ Insert } \\
\hline & Mean \pm SD & $\begin{array}{c}95 \% \\
\text { Confidence } \\
\text { Interval }\end{array}$ & Mean \pm SD & $\begin{array}{c}95 \% \\
\text { Confidence } \\
\text { Interval }\end{array}$ \\
\hline Total foot & $2.67 \pm 0.63$ & $2.96,2.39$ & $2.57 \pm 0.50$ & $2.79,2.34$ \\
\hline Rearfoot & $1.32 \pm 0.65$ & $1.62,1.03$ & $1.29 \pm 0.535$ & $1.53,1.05$ \\
\hline Medial midfoot & $0.22 \pm 0.12$ & $0.27,0.16$ & $0.13 \pm 0.08$ & $0.17,0.10$ \\
\hline Lateral midfoot & $0.33 \pm 0.12$ & $0.38,0.27$ & $0.28 \pm 0.16$ & $0.35,0.21$ \\
\hline Medial forefoot & $0.49 \pm 0.17$ & $0.56,0.41$ & $0.43 \pm 0.13$ & $0.49,0.37$ \\
\hline Mid forefoot & $0.42 \pm 0.11$ & $0.47,0.37$ & $0.47 \pm 0.13$ & $0.53,0.42$ \\
\hline Lateral forefoot & $0.28 \pm 0.08$ & $0.31,0.24$ & $0.28 \pm 0.11$ & $0.33,0.23$ \\
\hline Hallux & $0.37 \pm 0.13$ & $0.43,0.31$ & $0.36 \pm 0.09$ & $0.40,0.32$ \\
\hline Lesser toes & $0.36 \pm 0.10$ & $0.40,0.32$ & $0.31 \pm 0.11$ & $0.36,0.26$ \\
\hline
\end{tabular}

crossover cut task can be found in Table 8 . No differences existed for the remaining regions of the foot.

\section{DISCUSSION}

The purpose of our study was to determine the magnitude of change in plantar loading during a side cut and a crossover cut with the use of a rigid carbon fiber footplate.
Our results indicate that plantar loading increased during both tasks when the carbon insert was worn compared with performing the cutting tasks without the insert. During the crossover cut, the total foot peak pressure, maximum force, and force-time integral were all increased when the carbon footplate was used, while the contact area was decreased. The force-time integral is a measure of the area under the force-time curve and indicates not only how much the foot is being loaded but for how long. A decrease in the forcetime integral is generally believed to be beneficial for preventing injuries.

Previous literature ${ }^{20,21,28,29}$ on plantar-pressure distributions while performing these athletic tasks is limited. Queen et $\mathrm{a}^{20,28}$ examined differences in plantar loading during specific athletic tasks. During a side cut, most of the load affected the medial portion of the foot, whereas during the crossover cut, most of the load was beneath the lateral column of the foot. Therefore, the loading patterns differed between the cutting tasks.

The results of the shoe-only condition are consistent with previous research. ${ }^{20-22}$ During either type of cut while wearing the shank, the lateral column of the foot experienced increased pressures and decreased contact area when compared with cutting without the carbon inserts. When we examine the effect of plantar loading on the incidence of fifth metatarsal stress fractures, the area of interest is the lateral column, which includes the LFF and LMF. Placing a rigid carbon footplate in the shoes, however, resulted in higher plantar loading during the tasks studied, which was contrary to our expectations. Our findings show that when performing both the side cut and the crossover cut with the rigid insert, peak pressure increased in the LMF compared with completing these tasks without the shank. Additionally, in the crossover cut, peak pressure in the LFF increased. These results suggest that the carbon plate was not effective in decreasing plantar loading in a group of healthy participants. However, no information exists regarding the use of these insert in patients with fifth metatarsal stress fractures to understand if their response differs.

Although many factors have been identified that increase plantar loading and risk factors for fifth metatarsal fractures, ${ }^{2}$ it is important to understand that altered shear stress, which cannot be measured using current plantarloading systems, may also exist between the foot, shoe, and

Table 5. Peak Pressure During the Crossover Cutting Task, kPa

\begin{tabular}{|c|c|c|c|c|}
\hline \multirow[b]{3}{*}{ Foot Region } & \multicolumn{4}{|c|}{ Shoe Condition } \\
\hline & \multicolumn{2}{|c|}{ No Insert } & \multicolumn{2}{|c|}{ Insert } \\
\hline & Mean \pm SD & $\begin{array}{c}95 \% \\
\text { Confidence } \\
\text { Interval }\end{array}$ & Mean \pm SD & $\begin{array}{c}95 \% \\
\text { Confidence } \\
\text { Interval }\end{array}$ \\
\hline Total foot ${ }^{a}$ & $417.48 \pm 81.41$ & $454.09,380.88$ & $664.36 \pm 134.65$ & $724.91,603.82$ \\
\hline Rearfoot & $312.76 \pm 113.05$ & $363.59,261.92$ & $513.44 \pm 196.78$ & $601.92,424.96$ \\
\hline Medial midfoot & $178.08 \pm 50.13$ & $200.62,155.54$ & $175.80 \pm 45.18$ & $196.11,155.48$ \\
\hline Lateral midfoot & $263.88 \pm 88.41$ & $303.64,224.13$ & $360.27 \pm 150.05$ & $427.74,292.79$ \\
\hline Medial forefoot & $275.77 \pm 76.55$ & $310.19,241.35$ & $366.97 \pm 167.21$ & $442.15,291.78$ \\
\hline Mid forefoot & $293.30 \pm 68.69$ & $324.19,262.42$ & $449.82 \pm 165.00$ & $524.01,375.62$ \\
\hline Lateral forefoot & $308.30 \pm 86.84$ & $347.34,269.25$ & $420.16 \pm 136.74$ & $481.64,358.68$ \\
\hline Hallux & $323.36 \pm 86.98$ & $362.47,284.24$ & $494.81 \pm 169.91$ & $571.21,418.41$ \\
\hline Lesser toes & $212.88 \pm 59.94$ & $239.83,185.92$ & $281.17 \pm 94.11$ & $323.49,238.85$ \\
\hline
\end{tabular}

a Difference between shoe conditions. 
Table 6. Force-Time Integral During the Crossover Cutting Task, ns

\begin{tabular}{|c|c|c|c|c|}
\hline \multirow[b]{3}{*}{ Foot Region } & \multicolumn{4}{|c|}{ Shoe Condition } \\
\hline & \multicolumn{2}{|c|}{ No Insert } & \multicolumn{2}{|c|}{ Insert } \\
\hline & Mean $\pm S D$ & 95\% Confidence Interval & Mean $\pm S D$ & $95 \%$ Confidence Interval \\
\hline Total foot & $259436.09 \pm 55162.28$ & $284240.08,234632.10$ & $260921.05 \pm 54889.14$ & $285602.22,236239.88$ \\
\hline Rearfoot & $62.39 \pm 26.92$ & $74.49,50.28$ & $63.45 \pm 33.86$ & $78.68,48.23$ \\
\hline Medial midfoot & $12.22 \pm 5.98$ & $14.91,9.54$ & $6.59 \pm 3.70$ & $8.25,4.92$ \\
\hline Lateral midfoot & $44.09 \pm 16.68$ & $51.59,36.59$ & $46.11 \pm 16.64$ & $53.60,38.63$ \\
\hline Mid forefoot & $40.92 \pm 16.75$ & $48.45,33.39$ & $52.66 \pm 23.42$ & $63.19,42.13$ \\
\hline Lateral forefoot $^{a}$ & $35.13 \pm 13.93$ & $41.39,28.86$ & $40.48 \pm 12.91$ & $34.68,46.29$ \\
\hline Hallux & $25.02 \pm 8.07$ & $28.64,21.39$ & $31.30 \pm 10.47$ & $36.01,26.59$ \\
\hline Lesser toes & $23.38 \pm 11.02$ & $28.33,18.42$ & $26.41 \pm 11.12$ & $31.41,21.41$ \\
\hline
\end{tabular}

a Difference between shoe conditions.

rigid carbon footplate. Controlling shear stress could be critical in improving healing and decreasing the time lost due to injury. ${ }^{30}$ Therefore, the inability to quantify shear forces is a limitation of this study. Sex, shoe, and athletic task were controlled, but other factors might influence the pressure-distribution patterns, including type and speed of movement. ${ }^{20,28,31}$ The relative changes in plantar loading due to fatigue are unknown. Also unknown are the interactions of these various limitations in normal participants, in injured athletes, and during training and competition.

Our results do not support the hypothesis that the use of a rigid carbon footplate reduces plantar loading during cutting when compared with performing these same tasks in shoes without the footplate. The carbon footplate did not decrease loading beneath the lateral column in healthy people during agility activities, but a previous study ${ }^{32}$ in patients with midfoot arthritis indicated that the carbon shank was effective in reducing plantar loading during walking. The results of our study indicate that the use of a rigid carbon footplate actually increased loading in the lateral column of the foot during cutting tasks and would probably not be warranted for patients hoping to compete in agility sports while recovering from a fifth metatarsal stress fracture. The carbon plate could be detrimental to healing and ineffective in decreasing plantar loading beneath the lateral column of the foot. Future authors should examine the changes in plantar loading both with and without a

Table 7. Contact Area During the Crossover Cutting Task, Normalized Insole Contact Area

\begin{tabular}{lccccc}
\hline & \multicolumn{3}{c}{ Shoe Condition } \\
\cline { 2 - 4 } & \multicolumn{3}{c}{ No Insert } & \multicolumn{2}{c}{ Insert } \\
\cline { 2 - 3 } \cline { 5 - 6 } Confidence \\
Foot Region & Mean \pm SD & Interval & Mean \pm SD & $\begin{array}{c}\text { Confidence } \\
\text { Interval }\end{array}$ \\
\hline Total foot & $0.90 \pm 0.06$ & $0.93,0.88$ & $0.81 \pm 0.06$ & $0.84,0.79$ \\
Rearfoot & $0.24 \pm 0.02$ & $0.25,0.24$ & $0.22 \pm 0.03$ & $0.24,0.21$ \\
Medial midfoot & $0.11 \pm 0.03$ & $0.13,0.10$ & $0.07 \pm 0.03$ & $0.08,0.05$ \\
Lateral midfoot & $0.15 \pm 0.01$ & $0.16,0.15$ & $0.15 \pm 0.01$ & $0.15,0.15$ \\
Medial forefoot & $0.08 \pm 0.003$ & $0.08,0.07$ & $0.07 \pm 0.01$ & $0.07,0.07$ \\
Mid forefoot & $0.09 \pm 0.002$ & $0.09,0.09$ & $0.09 \pm 0.003$ & $0.09,0.08$ \\
Lateral forefoot & $0.08 \pm 0.01$ & $0.08,0.08$ & $0.08 \pm 0.01$ & $0.08,0.07$ \\
Hallux & $0.06 \pm 0.01$ & $0.06,0.06$ & $0.06 \pm 0.01$ & $0.06,0.05$ \\
Lesser toes & $0.09 \pm 0.02$ & $0.10,0.08$ & $0.09 \pm 0.02$ & $0.10,0.08$ \\
\hline
\end{tabular}

a Difference between shoe conditions.

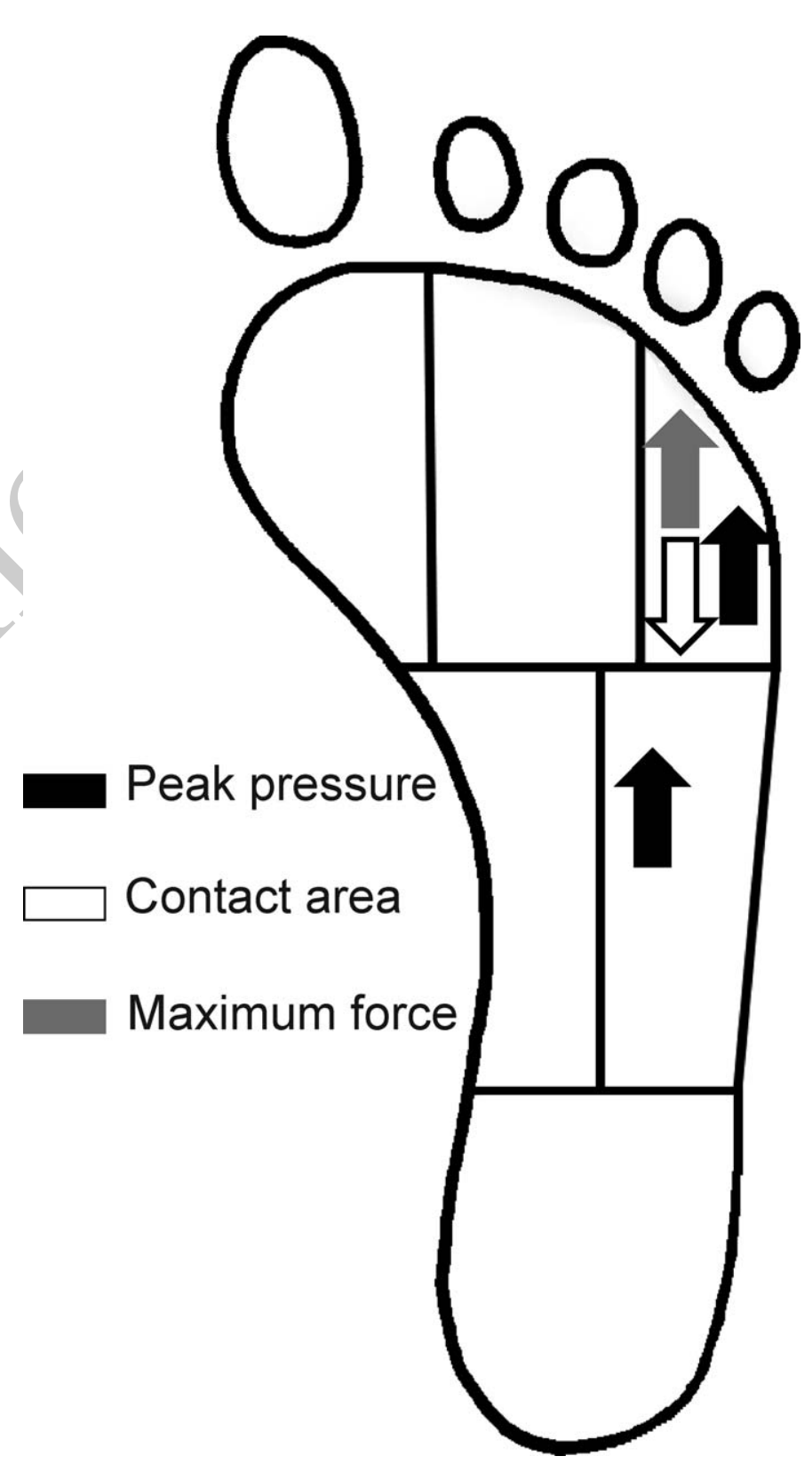

Figure 4. Changes in regional plantar pressure during the crossover-cutting task. Arrow indicates change in the specific variable when the carbon fiber footplate was worn in the shoe. 
Table 8. Maximum Force During the Crossover Cutting Task, Body Weight

\begin{tabular}{|c|c|c|c|c|}
\hline \multirow[b]{3}{*}{ Foot Region } & \multicolumn{4}{|c|}{ Shoe Condition } \\
\hline & \multicolumn{2}{|c|}{ No Insert } & \multicolumn{2}{|c|}{ Insert } \\
\hline & Mean $\pm S D$ & $\begin{array}{c}95 \% \\
\text { Confidence } \\
\text { Interval }\end{array}$ & Mean $\pm S D$ & $\begin{array}{c}95 \% \\
\text { Confidence } \\
\text { Interval }\end{array}$ \\
\hline Total foot & $2.22 \pm 0.33$ & 2.37, 2.07 & $2.34 \pm 0.40$ & $2.52,2.16$ \\
\hline Rearfoot & $1.13 \pm 0.38$ & $1.30,1.00$ & $1.23 \pm 0.45$ & $1.44,1.03$ \\
\hline Medial midfoot & $0.17 \pm 0.06$ & $0.20,0.14$ & $0.08 \pm 0.03$ & $0.10,0.07$ \\
\hline Lateral midfoot & $0.48 \pm 0.13$ & $0.54,0.42$ & $0.52 \pm 0.16$ & $0.60,0.45$ \\
\hline Medial forefoot & $0.29 \pm 0.10$ & $0.34,0.24$ & $0.23 \pm 0.10$ & $0.28,0.19$ \\
\hline Mid forefoot & $0.41 \pm 0.11$ & $0.46,0.37$ & $0.51 \pm 0.17$ & $0.58,0.43$ \\
\hline Lateral forefoot & $0.33 \pm 0.10$ & $0.38,0.29$ & $0.38 \pm 0.12$ & $0.43,0.33$ \\
\hline Hallux & $0.25 \pm 0.06$ & $0.27,0.22$ & $0.30 \pm 0.07$ & $0.33,0.26$ \\
\hline Lesser toes & $0.22 \pm 0.09$ & $0.26,0.18$ & $0.25 \pm 0.09$ & $0.29,0.21$ \\
\hline
\end{tabular}

carbon graphite footplate in patients with metatarsal fractures, which could aid in the understanding of whether this novel treatment is an effective treatment for reducing healing time and expediting return to activity.

\section{REFERENCES}

1. Hawkins RD, Fuller CW. A prospective epidemiological study of injuries in four English professional football clubs. Br J Sports Med. 1999;33(3):196-203.

2. Murphy DF, Connolly DAJ, Beynnon BD. Risk factors for lower extremity injury: a review of the literature. Br J Sports Med. 2003; 37(1):13-29.

3. Porter DA, Duncan M, Meyer SJ. Fifth metatarsal Jones fracture fixation with a $4.5-\mathrm{mm}$ cannulated stainless steel screw in the competitive and recreational athlete: a clinical and radiographic evaluation. Am J Sports Med. 2005;33(5):726-733.

4. Queen RM, Nunley JA. Fifth metatarsal stress fractures: the role of plantar loading in understanding injury risk factors. Low Extrem Rev [serial online]. 2009. http://www.lowerextremityreview.com/issues/ fifth-met-stress-fracture-load-based-risk-factors.

5. McBryde A. Risk factors for lower extremity injury: a review of the literature. Clin Sports Med. 1985;4:737-752.

6. Simkin A, Leichter I, Giladi M, Stein M, Milgrom C. Combined effect of foot arch structure and an orthotic device on stress fractures. Foot Ankle. 1989;10(1): 25-29.

7. Giladi M, Milgrom C, Stein M, et al. The low arch, a protective factor in stress fractures. Orthop Rev. 1985;14(11):81-84.

8. Clapper MF, O'Brien TJ, Lyons PM. Fractures of the fifth metatarsal: analysis of a fracture registry. Clin Orthop Relat Res. 1995;315:238 241.

9. DeLee JC, Evans JP, Julian J. Stress fractures of the fifth metatarsal. Am J Sports Med. 1983;11(5):349-353.

10. Torg JS, Balduini FC, Zelko RR, Pavlov H, Peff TC, Das M. Fractures of the base of the fifth metatarsal distal to the tuberosity: classification and guidelines for non-surgical and surgical management. J Bone Joint Surg Am. 1984;66(2):209-214.

11. Wright RW, Fischer DA, Shively RA. Refracture of proximal fifth metatarsal (Jones) fracture after intramedullary screw fixation in athletes. Am J Sports Med. 2000;28(5):732-736.
12. Zelko RR, Torg JS, Rachun A. Proximal diaphyseal fractures of the fifth metatarsal-treatment of the fractures and their complications in athletes. Am J Sports Med. 1979;7(2):95-101.

13. Josefsson PO, Karlsson M, Redlund-Johnell I, Wendeberg B. Jones fracture: surgical versus nonsurgical treatment. Clin Orthop Relat Res. 1994;299:252-255.

14. Kelly IP, Glisson RR, Fink C, Easley ME, Nunley JA. Intramedullary screw fixation of Jones fractures. Foot Ankle Int. 2001;22(7):585589 .

15. Larson CM, Almekinders LC, Taft TN, Garrett WE. Intramedullary screw fixation of Jones fractures: analysis of failure. Am J Sports Med. 2002;30(1):55-60.

16. Ferrari J, Watkinson D. Foot pressure measurement differences between boys and girls with reference to hallux valgus deformity and hypermobility. Foot Ankle Int. 2005;26(9):739-747.

17. Holmes GB Jr, Timmerman L, Wilits NH. Practical considerations for the use of the pedobarograph. Foot Ankle Int. 1991;12(2):105108 .

18. Sims EL, Hardaker WM, Queen RM. Gender differences in plantar loading during three soccer-specific tasks. Br J Sports Med. 2008; 42(4):272-277.

19. Fernandez-Fairen M, Guillen J, Busto JM, Roura J. Fractures of the fifth metatarsal in basketball players. Sports Med. 1999;7(6):373377.

20. Queen RM, Haynes BB, Hardaker WM, Garrett WE Jr. Forefoot loading during 3 athletic tasks. Am J Sports Med. 2007;35(4):630 636.

21. Eils E, Streyl M, Linnenbecker S, Thorwesten L, Völker K, Rosenbaum D. Characteristic plantar pressure distribution patterns during soccer-specific movements. Am J Sports Med. 2004;32(1): $140-145$.

22. Wong PL, Chamari K, Mao de W, Wisloff U, Hong Y. Higher plantar pressure on the medial side in four soccer-related movements. $\mathrm{Br} \mathrm{J}$ Sports Med. 2007;41(2):93-100.

23. Queen RM, Crowder TT, Johnson H, Ozumba D, Toth AP. Treatment of metatarsal stress fractures: case reports. Foot Ankle Int. 2007;28(4):506-510

24. Gampp J, Willson J, Kernozek T. The plantar loading variations to uphill and downhill gradients during treadmill walking. Foot Ankle Int. 2000;21(3):227-231.

25. Urry SR. Redistribution of foot pressure in healthy adults during sideslope walking. Foot Ankle Int. 2002;23(12):1112-1118.

26. Willson JD, Kernozek TW. Plantar loading and cadence alterations with fatigue. Med Sci Sports Exerc. 1999;31(12):1828-1833.

27. Queen RM, Mall NA, Nunley JA, Chuckpaiwong B. Differences in plantar loading between flat and normal feet during different athletic tasks. Gait Posture. 2009;29(4):582-586.

28. Queen RM, Charnock BL, Garrett WE Jr, Hardaker WM, Sims EL, Moorman CT III. A comparison of cleat types during two footballspecific tasks on FieldTurf. Br J Sports Med. 2008;42(4):278-284.

29. Santos D, Carline T, Flynn L, et al. Distribution of in-shoe dynamic foot pressures in professional football players. The Foot. 2001;11(1): $10-14$.

30. Ekstrand J, Nigg BM. Surface-related injuries in soccer. Sports Med. 1989;8(1):56-62.

31. Rosenbaum D, Hautmann S, Gold M, Claes L. Effects of walking speed on plantar pressure patterns and hindfoot angular motion. Gait Posture. 1994;2(3):191-197.

32. Rao S, Baumhauer JF, Nawoczenski DA. Is barefoot regional plantar loading related to self-reported foot pain in patients with midfoot osteoarthritis. Osteoarthr Cartilage. 2011;19(8):1019-1025. 
Queries for attr-49-02-24

This manuscript/text has been typeset from the submitted material. Please check this proof carefully to make sure there have been no font conversion errors or inadvertent formatting errors. Allen Press.

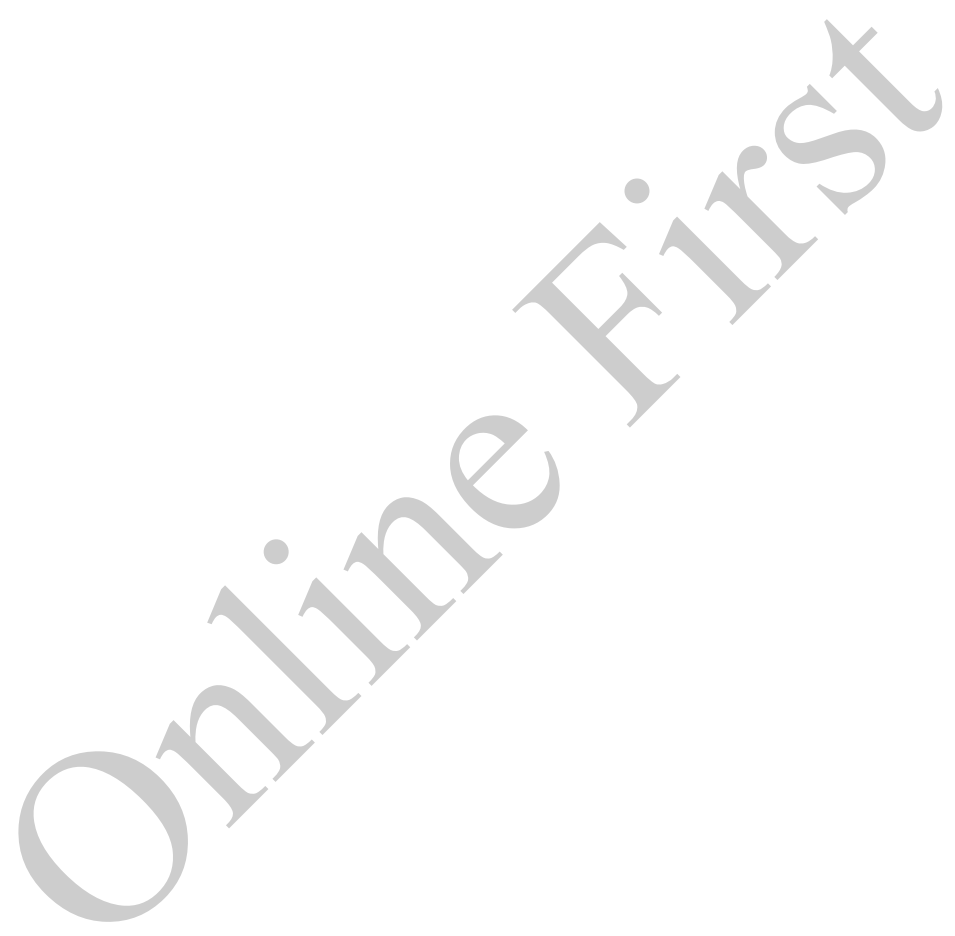

